\title{
REVIEWS
} ANDRZEJ BASIŃSKI ${ }^{3}$ E, F

\section{Problems and Barriers in Ensuring Effective Acute and Post-Operative Pain Management - an International Perspective}

${ }^{1}$ Department of General Nursing, Medical University of Gdańsk, Poland

${ }^{2}$ Department of Anesthesiology and Intensive Care, Obodzińskiej-Król Memorial Hospital, Malbork, Poland

${ }^{3}$ Clinical Emergency Department, Medical University of Gdańsk, Poland

A - research concept and design; B - collection and/or assembly of data; C - data analysis and interpretation;

$\mathbf{D}$ - writing the article; $\mathbf{E}$ - critical revision of the article; $\mathbf{F}$ - final approval of article

\begin{abstract}
Pain management originated at the turn of the 1960s and 70s in the United States, and spread to Western Europe almost a decade later. It is estimated today that a lack of adequate pain management affects $80 \%$ of the global population, and is a serious problem in over 150 countries. At the national level, the greatest burden of inadequate pain management is borne by the elderly, pregnant and breastfeeding women, children, people coping with addictions to harmful substances, and the mentally ill. In spite of enormous progress, there are still significant barriers to comprehensive pain management. Pain management should be considered a priority. It is an interdisciplinary task requiring the cooperation of the whole medical staff. The current review of literature revealed a number of factors limiting the possibility of achieving effective pain management, related to healthcare systems, medical staff and patients (Adv Clin Exp Med 2015, 24, 5, 905-910).
\end{abstract}

Key words: barriers, acute pain, post-operative pain, old age.

Pain management originated at the turn of the 1960s and 70s in the United States and spread to Western Europe almost a decade later. The theoretical foundations of the phenomenon of pain, published in 1965 by two American physicians, Melzack and Wall, initiated a long-lasting process of changing attitudes in the medical community toward the problem of pain [1]. Several studies conducted in the USA in the 1970s clearly demonstrated that the healthcare system lacked individuals or teams who would be responsible for pain therapy. The second conclusion drawn from these studies was the statement that it was not sufficient just to disseminate information on pain therapy, but that pain therapy should be made a priority $[2,3]$.

That was over three decades ago. In the meantime, the United States has introduced programs firmly defining pain management as a top priority in patients' rehabilitation, particularly in such areas as palliative care, interdisciplinary pain management, post-operative pain therapy or labor pain management. Pain therapy assumed organizational forms. Organizations such as the American Pain Society and the National Hospice Organization were established as early as 1978. In 1986, the International Pain Foundation was set up, with the goal of providing support for public and professional education regarding painful conditions and their treatment. Moreover, specialist literature partly or totally focused on pain management issues developed [4]. Practically a decade after the establishment of the theoretical foundations of pain management in the United States, the problem of pain started to gain importance in Great Britain too. Since 1995 the number of hospitals with acute pain service (APS) teams has been increasing. The creation of such teams has obviously raised the awareness that adequate pain management translates into the well-being of patients. However, despite multiple agreements with professional 
organizations, some hospitals still do not have their own APSs, and recent data show that some APSs are unable to offer in-hospital services due to financial problems [5]. It is now estimated that a lack of adequate pain management affects $80 \%$ of the global population, posing a serious problem in over 150 countries. At the national levels (e.g. in China, Great Britain, the Netherlands, Spain, Turkey, USA) the greatest burden of inadequate pain management is borne by the elderly, pregnant and breastfeeding women, children, people coping with addictions to harmful substances, and the mentally ill [6-15]. There are still significant barriers to comprehensive pain management, limiting the capacity for effective pain management. The Agency for Healthcare Research and Quality in the USA distinguishes the following types of barriers to pain management: healthcare system-related, medical staff-related and patient-related $[8,10,16]$.

\section{Healthcare System-Related Barriers}

In the healthcare systems of many countries there are fundamental barriers hindering effective pain management. There are no clearly defined standards and pain management is not considered a priority. Statistics indicate that patients are likely not to receive analgesic medications when required and treatment is likely to be delayed or ineffective [10,12].

Depending on the expenditures on health care in different countries, diverse working models of APS teams have been developed across the world. There are significant differences in the organization of such teams in the United States, Scandinavia and other regions of Europe. In Poland, pain management is usually based on nursing care supervised by an anesthesiologist or surgeon. The work of nurse-physician teams is performed within the framework of their regular work contracts and duty rosters, entailing no additional expenses for the hospital but putting an additional workload on nurses, in a situation where there are already unfavorable nurse-to-patient ratios. In surgical wards in Poland, it is not uncommon to find 8 to 20 (or more) patients per nurse, as hospitals do not observe nurse staffing standards [17]. The Polish healthcare system is likely to continue having problems with the quality of pain management unless this issue is dealt with. Turkish nurses, for instance, cope with a similar problem, with 8 to 10 patients per nurse in surgical wards. Staff shortages are still a barrier to optimum patient care in developing countries but do not have to be a barrier in developed countries [8].
Recent years have seen the development of new analgesic medications and advanced drug delivery systems. Interest in epidural anesthesia and patient-controlled analgesia (PCA) methods has grown. In Poland, pursuant to legislation regulating the nursing and midwifery professions, only nurses who have completed a qualifying or specialization course in "Anesthesiological Nursing and Intensive Care" or a specialization course for nurses and midwives in "Acute Pain Therapy in Adults" are authorized to administer drugs. This is currently a serious problem since there are few nurses with adequate qualifications; therefore physicians need to be involved [18]. Some hospitals are also affected by shortages of medications and specialist equipment, e.g. PCA pumps [19].

Some healthcare centers use no special tools for pain assessment, nor do they allocate enough time and space in the patients' charts for documentation of pain intensity information [8]. In 2008, Yanuka et al. demonstrated that the introduction of pain management protocols in emergency departments led to an increase in the percentage of patients receiving analgesia from $33.4 \%$ to $99 \%$ [20]. On average, patients in Great Britain are administered analgesic drugs only 3 h 46 min following admission if the pain is moderate, and after $1 \mathrm{~h} 12 \mathrm{~min}$ if the pain is described as severe [21]. In a retrospective study of charts, Somers et al. examined 262 children and found that the implementation of the protocol had led to a significant increase in the number of children who were administered analgesic treatment within $30 \mathrm{~min}$ of triage [22].

Another problem is associated with the way many healthcare systems are organized, affording limited access to medical specialists, pain management centers or analgesics. A recent questionnaire conducted in the USA showed that there are about 6 pain management specialists for every 100,000 patients with persistent pain [21].

\section{Healthcare Staff-Related Barriers}

In the literature there are reports showing that, due to the subjective character of pain, the attitudes and convictions of medical staff may contribute to insufficient pain management. Since the late 1990s, scientific research has shown that the majority of healthcare professionals have below-average knowledge and skills related to pain management. The educational programs in most medical, nursing and pharmaceutical colleges do not include pain management issues to an extent adequate to the needs. Experienced physicians and nurses do not have adequate motivation to 
broaden their knowledge of pain [16]. Additionally, doctors and nurses are not able to work as a team, which is a prerequisite for ensuring good quality pain management in hospitals. Elcigil et al. demonstrated in their study that out of 247 nurses examined, $70 \%$ had difficulty contacting or communicating with physicians to discuss patients' pain management [8].

\section{Physician-Related Barriers}

Among the most difficult barriers to effective pain management to overcome are the management patterns in experienced physicians as opposed to novices [16]. In the study by Elcigil et al., two of the most frequent physician-related barriers were a lack of regular and consistent pain assessment by physicians (63\%), and their indifference to the problem (54\%) [8]. In Great Britain, in spite of national guidelines on the management of pain disorders, a study by Lewis et al. showed that they were not sufficiently followed by practicing physicians [23]. An analysis of available studies shows that clinicians very often understate the level of pain in patients and demonstrate a distrust of pain rating by nurses $[8,24,25]$. Wallace et al. point out that physicians' inadequate knowledge remains a significant barrier to pain management, as clinicians do not seem to notice the gaps in their knowledge or the need to fill them $[8,26]$. A frequent reason for inadequate pain management in emergency departments is the conviction that analgesia conceals clinical symptoms, which may lead to worse treatment outcomes [20,27]. Over three quarters of physicians postpone the administration of opioid analgesia to patients until a surgical consultation is carried out [20]. Physicians are reluctant to prescribe adequate analgesics because of concerns about possible addiction or overdosing in patients with delirium or dementia, for example. The issue of inadequate pain management is regarded as a multifaceted one, but clinician-related barriers are a principal cause for concern [28].

\section{Nurse-Related Barriers}

Lack of knowledge and lack of time for continuing education are the barriers to effective pain management most frequently mentioned by nurses [28]. In a study of nursing textbooks concerning the issue of pain management in the UK, Ferrell et al. found that only $0.5 \%$ of the total content concerned pain [7]. Workload is the key problem in pain management supervised by nurses. Nurses have no time to educate patients about pain, nor do they use non-pharmacological methods of pain management. Non-pharmacological methods of pain management remain a neglected therapeutic option [8, 28].

An analysis of the studies reveals that nurses' opinions influence pain management and their use of analgesia $[7,8,16]$. A study by Coker et al. found that nurses significantly underestimate the assessment of pain intensity and its consequences, the level of pain at rest and in motion as well as overall pain intensity [7]. In that study, only $15 \%$ of nurses declared that they administered pain management for $24 \mathrm{~h}$ a day, even though $79 \%$ of nurses thought that round-the-clock administration of medications was the recommended method in contrast to on-demand analgesic administration. There is evidence that as a result of staff shortages and increasing workloads, nurses put nursing procedures first in patient care, while attaching less importance to such aspects of care as pain management [28].

According to the recommendations of pain management societies, the most appropriate routes of analgesic administration are intravenous and oral, while studies and the authors' own experience show that analgesics are more frequently administered by the intramuscular route, which very often applies to opioids. This route of drug delivery is chosen because of an inability to connect the patient to a pulse oximeter to monitor any possible adverse effects of the drug.

\section{Patient-Related Barriers}

Pain management in certain special groups of patients, such as pregnant women, children and the elderly, can prove an extremely difficult task.

Pregnant women who experience pain are a special group of patients for physicians because of the conviction that the majority of analgesic drugs cross the trophoblast/placental barrier and may be responsible for many adverse reactions, including fetal death, teratogenic effects, inhibition of intrauterine fetal growth, psychophysical development disorders and increased incidence of cancer in the neonatal and infantile period [29].

Assessment of pain in newborn babies, infants and children with developmental disorders is particularly difficult. A child's perception and communicative abilities depend on their intellectual and social development. There are popular misconceptions that infants are less sensitive to pain or have a limited capacity for remembering pain because of their immature nervous systems. A child suffers from post-operative pain in the same way an adult does. In fact, pain experienced in the neonatal period can intensify behavioral and affective 
reactions during subsequent pain events. With regard to older children, physicians may mistakenly consider the parents to be more reliable in assessing pain intensity than the children suffering from pain themselves [30].

Inadequate management of acute pain can be more noticeable in elderly patients with cognitive disorders, depression, agitation, concomitant conditions or social isolation, who fail to report all their symptoms and whose response to analgesics is different [31]. Dementia is a barrier to the estimation of pain, as it is a condition characterized by memory loss, personality changes and a loss of such functions as good sight, abstract thinking or linguistic abilities. Moreover, pain-related behavior can be absent or difficult to interpret. However, symptoms attributed to dementia may actually be associated with pain: Aggressive behavior, for instance, can be a defensive reaction on the part of people unable to express that they are in pain [32].

Due to sensory and perceptive disorders, elderly patients may find it difficult to complete numerical pain rating scales from 0 to 10 [33-35]. Elderly patients may underrate their pain because some patients mistakenly believe that pain is part of the normal ageing process. In other cases, such as cancer pain, the rating may be understated because of fear of disease progression. Patients may be affected by fatalism and the unjustified conviction that if pain can be helpful in the diagnosis, then it must have therapeutic properties [6].

It is a popular but false belief that elderly people do not feel pain as acutely as other groups of patients. Elderly patients are often affected by numerous conditions and potential sources of pain that are likely to complicate interpretation of their pain symptoms [36, 37]. This group of patients, and those who are less educated, may be reluctant to take analgesic medications for fear of adverse reactions or of becoming addicted [17]. According to some studies, a frequent barrier to optimum pain management is elderly patients' reluctance to cause trouble to the healthcare staff, which results in the non-reporting of pain symptoms. $\mathrm{Pa}$ tients may think that mentioning pain will divert doctors' attention from the underlying disease; also, the view that "good" patients do not talk about pain persists among the elderly $[35,38]$. An analysis of available multi-center studies shows that obstacles to adequate treatment in Western countries include ethnic and racial discrimination, age and gender. Among the patients studied, women were administered more analgesics than men. In addition, elderly patients had to wait longer for pain medications and received much lower doses and smaller amounts of opioid analgesics [10].

\section{Summary}

The current review of the literature revealed a number of factors limiting the possibilities of efficient pain management. These problems go beyond a single hospital or even country; they are global problems. Despite available means of post-operative pain relief, they are still not sufficiently used. Unsatisfactory cooperation between physicians and nurses and inadequate analgesic prescribing practices have a decidedly negative impact on pain management [39]. Obstacles encountered by nurses could be alleviated by adequate professional cooperation between physicians and nurses; with this goal in mind, meetings should be organized for the two professional groups to discuss pain management issues and analyze suggested procedures. Insufficient pain management is not an insoluble problem [8]. Education is effective in removing the barriers to pain assessment and management. There should be regular and permanent educational programs for all medical professionals participating in pain management $[18,40]$. In developing countries, where healthcare resources are insufficient, it is vital to use evidence-based practices (EBPs). The implementation of EBPs in post-operative pain management may definitely improve the quality of medical services and healthcare. Post-operative pain management in Poland is in need of significant improvement; the Polish Society for Pain Research (PTBB) has therefore taken measures to implement post-operative pain management standards. What is now needed is further research into awareness of and attitudes toward pain management, as well as positive steps to support the development of adequate practices [18].

\section{References}

[1] Melzack R, Wall PD: Pain mechanisms: a new theory. Science 1965, 150, 975.

[2] Fagerhaugh SY: Pain expression and control on a burn unit. Nurs Outlook 1974, 22, 647.

[3] McCaffery M, Beebe A: Pain: Clinical Manual for Nursing Practice. The C.V Mosby Company 1989.

[4] McCaferry M: Nursing Practice Theories related to Cognition. Bodily Pain and Man-Environment Interactions. University of California, Los Angeles 1968.

[5] De Rond M, De Wit R, Van Dam F: The implementation of a pain monitoring programme for nurses in daily clinical practice; results of a follow up study in five hospitals. J Adv Nurs 2001, 29, 590-598. 
[6] Lynch M: Pain as the Fifth Vital Sign. J Intra Nurs 2001, 24, 85-94.

[7] Coker E, Papaioannou A, Kaasalainen S, Dolovich L: Nurses perceived barriers to optimal pain management in older adults on acute medical units. Appl Nurs Res 2010, 23, 139-146.

[8] Elcigil A, Maltepe H, Esrefgil G, Mutafoglu K: Nurses' perceived barriers to assessment and management of pain in a university hospital. J Pediatr Hematol Oncol 2011, 33, 33-38.

[9] Egan M, Cornally N: Identifying barriers to pain management in long-term care. Nurs Older People 2013, 25, 25-31.

[10] Motov SM, Khan AN: Problems and barriers of pain management in the emergency department: Are we ever going to get better? J Pain Res 2009, 2, 5-11.

[11] Sullivan LW, Eagel BA: Leveling the Playing Field: Recognizing and Rectifying Disparities in Management of Pain. Pain Med 2005, 6, 5-10.

[12] Taylor AL, Gostin LO, Pagonis KA: Ensuring Effective Pin Treatment. A National and Global Perspective. JAMA 2008, 299, 89-91.

[13] van Boekel RL, Steegers MA, Verbeek-van Noord I, van der Sande R, Vissers KC: Acute pain services and postsurgical pain management in the Netherlands: a survey. Pain Prac 2015, 15, 447-454.

[14] Vallano A, Malouf J, Payrulet P, Baños JE: Prevalence of pain in adults admitted to Catalonian hospitals: a crosssectional study. Eur J Pain 2006, 10, 721-731.

[15] Zhang CH, Hsu L, Zou BR, Wang HY, Huang J: Effects of a pain education program on nurses' pain knowledge, attitudes and pain assessment practice in China. J Pain Symptom Manage 2008, 36, 616-627.

[16] Duignan M, Dunn V: Barriers to pain management in emergency departments. Emergency nurse 2008, 15, 30-34.

[17] Gaweł G: Obciążenie pracą pielęgniarek pracujących w systemie zmianowym 12-godzinnym. Pielęg XXI Wieku $2003,3,77-82$.

[18] Mędrzycka-Dąbrowska W, Ogrodniczuk M, Dąbrowski S: Udział pielęgniarki w procesie terapii bólu pooperacyjnego - część I. Anest Ratow 2012, 6, 221-227.

[19] Misiołek H, Kwosek A: Zasady organizacji Zespołu Leczenia Bólu opartego na analgezji regionalnej. Ból 2009, 10, 60-66.

[20] Yanuka M, Soffer D, Halpern P: An interventional study to improve the quality of analgesia in the emergency department. Can J Emerg Med 2008, 10, 435-439.

[21] Wolfe JM, Lein DY, Lenkoski K: Analgesic administration to patients with an acute abdomen: a survey of emergency medicine physicians. Am J Emerg Med 2000, 18, 250-253.

[22] Somers LJ, Beekett MW, Sedgwick PM, Hulbert DC: Improving the delivery of analgesia to children in pain. Emerg Med J 2001, 18, 159-161.

[23] Lewis LM, Lasater LC, Ruoff BE: Failure of a chest pain clinical policy to modify physician evaluation and management. Ann Emerg Med 1995, 25, 9-14.

[24] Goodacre SW, Roden RK: A protocol to improve analgesia use in the accident and emergency department. J Acid Emerg Med J 2001, 13, 177-622.

[25] Drayer RA, Henderson J, Reidenberg M: Barriers to Better Pain Control in Hospitalized Patients. J Pain Symptom Manage 1999, 17, 434-440.

[26] Ross S, Grant A, Counsell C, Gillespie W, Russell I, Prescott R: Barriers to Participation in Randomised Controlled Trials: A Systematic Review. J Clin Epidemiol 1999, 52, 1143-1156.

[27] Grant PS: Analgesia delivery in the ED. Am J Emerg Med 2006, 24, 806-809.

[28] Coulling S: Nurses' and doctors' knowledge of pain after surgery. Nurs Stand 2005, 19, 41-49.

[29] Rekomendacje dotyczące postpowania przeciwbólowego w ginekologiii płożnictwie. Część II: Leczenie bólu u kobiet ciężarnych, rodzących oraz w połogu. Ginekol Pol 2008, 79, 567-577.

[30] Verghese ST, Hannallah RS: Acute pain management in children. J Pain Res 2010, 3, 105-123.

[31] Cavalieri TA: Management of Pain in Older Adults. J Am Osteopath Assoc 2002, 102, 481-485.

[32] Aubrun F, Marmion F: The elderly patient and post-operative pain treatment. Best Pract Res Clin Anaesthesiol 2007, 21, 109-127.

[33] Kaye AD, Baluch A, Scott JT: Pain Management in the Elderly Population: A Review. Ochsner J 2010, 10, $179-187$.

[34] Taylor LJ, Harris J, Epps CD, Herr K: Psychometric evaluation of selected pain intensity scales for use with cognitively impaired and cognitively intact older adults. J Reh Nurs 2013, 30, 55-61.

[35] Misiołek H, Mayzner-Zawadzka E, Dobrogowski J, Wordliczek J: Zalecenia 2011 postępowania w bólu ostrym i pooperacyjnym. Ból 2011, 12, 9-33.

[36] Aubrun F, Marmion F: The elderly patient and post-operative pain treatment. Best Pract Res Clin Anaesthesiol 2007, 21, 109-127.

[37] Ware LJ, Bruckenthal P, Gail CD, O’Conner-Von SK: Factors that influence patient advocacy by pain management nurses: results of the American society for pain management nursing survey. J Am Pain Manage Nurs 2011, $12,25-32$.

[38] Herr KA, Spratt K, Mobily PR, Richardson G: Pain intensity assessment in older adults: use of experimental pain to compare psychometric properties and usability of selected pain scales with younger adults. Clin J Pain 2004, 20, 207-219.

[39] Horbury C, Henderson A, Bromley B: Influences of patient behavior on clinical nurses' pain assessment: implications for continuing education. J Contin Educ Nurs 2005, 36, 18-24.

[40] Harmer M, Davies KA: The effect of education, assessment and a standardised prescription on post-operative pain management. The value of clinical audit in the establishment of acute pain services. Anaesthesia 1998, 53, 424-430. 


\section{Address for correspondence:}

Wioletta Mędrzycka-Dąbrowska

Department of General Nursing

Medical University of Gdańsk

Dębinki 7

80-227 Gdańsk

Poland

E-mail: wioletta.medrzycka@gumed.edu.pl

Conflict of interest: None declared

Received: 8.05.2014

Revised: 3.07.2014

Accepted: 11.07.2014 